\title{
RESEARCH
}

Open Access

\section{Social integration and mental health - a decomposition approach to mental health inequalities between the foreign-born and native-born in Sweden}

\author{
Anna Brydsten * (D), Mikael Rostila and Andrea Dunlavy
}

\begin{abstract}
Background: The increasing mental health inequalities between native- and foreign-born persons in Sweden is an important public health issue. Improving social integration has been stressed as a key strategy to combat this development. While a vast amount of studies have confirmed the importance of social integration for good mental health, less is known about the role of different types of social integration, and how they relate to mental health inequalities. This study aimed to examine the extent to which indicators of social integration explained mental health inequalities between the native- and foreign-born.

Methods: Based on the Health on Equal Terms survey from 2011/2015 in Västra Götaland, Sweden $(n=71,643)$, a non-linear Oaxaca-Blinder decomposition analysis was performed comparing native- and foreign-born individuals from Nordic-, European- and non-European countries. The General Health Questionnaire was used to assess psychological distress, while 11 items assessed employment conditions and economic disparities, social relations, and experiences of discrimination to measure different aspects of social integration.

Results: Differences in social integration explained large proportions of observed mental health differences between the native- and foreign-born. Important indicators included low levels of social activity (20\%), trust in others (17\%) and social support (16\%), but also labour market disadvantages, such as being outside the labour market (15\%), unemployment $(10 \%)$ and experiencing financial strain (16\%). In analyses stratified by region of origin, low trust in others and discrimination contributed to the mental health gap between the native-born and European-born (17 and 9\%, respectively), and the native-born and non-European-born (19 and 10\%, respectively). Precarious labour market position was a particularly important factor in the mental health gap between the native-born and Nordicorigin (22\%), and non-European origin (36\%) populations.

Conclusion: Social integration factors play a central role in explaining the mental health inequality between natives and migrants in Sweden. Our findings suggest that public health actions targeting mental health gaps could benefit from focusing on inequalities in social and economic recourses between natives and migrants in Sweden. Areas of priority include improving migrants' financial strain, as well as increasing trust in others and social support and opportunities for civic engagement.
\end{abstract}

Keywords: Mental health inequality, Foreign-born, Social integration, Oaxaca-Blinder decomposition, Sweden

\footnotetext{
* Correspondence: anna.brydsten@su.se

Department of Public Health Science, Centre for Health Equity Studies

(CHESS), Stockholm University/Karolinska Institutet, SE-105 91 Stockholm,

Sweden
}

(c) The Author(s). 2019 Open Access This article is distributed under the terms of the Creative Commons Attribution 4.0 International License (http://creativecommons.org/licenses/by/4.0/), which permits unrestricted use, distribution, and reproduction in any medium, provided you give appropriate credit to the original author(s) and the source, provide a link to the Creative Commons license, and indicate if changes were made. The Creative Commons Public Domain Dedication waiver (http://creativecommons.org/publicdomain/zero/1.0/) applies to the data made available in this article, unless otherwise stated. 
Recent evidence has suggested that mental health inequalities between native- and foreign-born persons in Sweden are increasing [1]. In order to combat this negative development, policy makers and public health researchers have proposed increasing social integration as a key strategy to reduce the prevalence of poor mental health among migrants [2-4]. Social integration is a multidimensional concept describing the capacity of people to participate in social, cultural, economic and political life in the community [5]. For migrants, who commonly face several social and economic adversities and challenges, lack of social integration may lead to increased stress and poor psychological well-being [6-9]. However, although several studies have linked migrants' integration with health [10-14], most have examined the influence of only one or two dimensions of social integration, and have not directly assessed the extent to which different social integration factors might contribute to mental health inequalities between native- and foreign-born individuals. The present study aims to address this knowledge gap by using a decomposition analysis to assess the relative contribution of different social integration factors, such as labour market and economic adversities, social relations, and discrimination, in explaining mental health gaps between natives and groups of migrants in Sweden.

\section{Background}

In recent years, the number of migrants has increased substantially in Sweden. In 2017, nearly 1.9 million people living in Sweden were foreign-born, corresponding to approximately every sixth person in the population [15]. With these sociodemographic changes, ensuring a healthy population is of high importance. Although migrants tend to show lower mortality rates relative to natives [16], they also tend to report poorer self-rated health, higher rates of long-term illness and poorer mental health, such as depression and anxiety $[8,12,17-19]$. The roots of mental health inequalities are often attributed to social integration issues, such as difficulty getting established in the labour market, social and economic deprivation, as well as social isolation and discrimination $[2,8,20]$.

Employment has been the most studied aspect of social integration among migrants, as it entails active participation in society. Stable employment with good working conditions can provide multiple social and psychological benefits, including social interaction with co-workers, increased self-esteem, sense of identity, and daily time structures [21]. For migrants in particular, employment is also a key factor in resettlement in a new society, allowing for financial independence and sense of belonging. However, migrants in Sweden typically have higher rates of unemployment as well as temporary employment than natives [22]. They are also experience greater economic disadvantage as well as poorer psychosocial working conditions than the natives [23]. All of these factors have been associated with poor mental health among migrants $[8,13,14,24-26]$, as well as the general population [27-29]. Unemployment, precarious employment and economic deprivation may also act as moderating factors through socioeconomic circumstances of low education, poor working conditions and low income, leading to psychological distress. Due to migrants' marginalised position on the labour market, unemployment may be particularly important social determinant of mental health inequality.

Labour market integration are also related to other dimensions of social integration, such as the formation of social relationships and networks. Social relationships may be particularly important for migrants' mental health because they often have access to fewer social arenas compared to native-born [10,30]. Studies of migrant mental health have noted the importance of social relationships and social networks in the country of residence, which can influence migrants' ability to adapt and cope with their new social environment [3, 31]. Social relationships characterised by social and practical support and trust in others can promote social integration and well-being, reduce stress, and buffer against poor mental health $[8,14,32,33]$. Participation in social activities, such as sports, gatherings with friends and family, and political and religious workshops, have been identified as activities that promote a good social environment, political and democratic platforms, and a foundation for trust in other people [32, 34], which in turn can promote social resilience and mental health [35]. In addition to the economic, labour market and social network disadvantages often seen among migrants, they also may face social integration barriers to a greater extent than natives. Previous studies have shown that incidents of physical or verbal harassment and discrimination among migrants' have a deeply adverse impact on social integration [8], and an increased risk of poor mental health [36], low quality of life [34] and lower self-reported health status [37], particularly among non-white immigrant women $[8,38,39]$.

These findings highlight the mental health importance of social integration in the destination country. Yet, it is likely that migrants' degree of social integration and the relative importance of different social integration factors have a differential impact on mental health depending on country of origin [24]. For example, due to variation in experiences of stressful migration processes, language and cultural barriers, and exposure to threats, violence and discrimination, social integration and mental health is likely to vary within migrant populations [24, 34, 40]. It is therefore important to explore the magnitude of mental health inequalities between natives and different groups of migrants, and the differential impact of 
distinct types of social integration on such mental health inequalities. In this study, we used the Oaxaca-Blinder decomposition for non-linear models to investigate the relative contributions of variations in the distributions of social integration indicators as well as their differential effects in producing mental health inequalities between natives and groups of migrants in Sweden. With this approach, in comparisons to logistic regression models with interaction terms, we can quantify both the degree to which each indicator of social integration and the combined overall measure of social integration explain the mental health inequality between natives and migrants. The specific aim of this study was to assess 1 ) the extent to which different indicators of social integration (employment conditions, economic disparities, social relations, and experiences of discrimination) may explain differences in psychological distress between the native- and foreign-born, and 2) if the contribution of different indicators of social integration in the formation of mental health inequalities differs among groups of foreign-born (Nordic, European and non-European origin).

\section{Methods}

\section{Data material}

Cross-sectional data were obtained from the Health on Equal Terms (HET) surveys from 2011 and 2015 for Västra Götaland. The HET-survey is administered by the Public Health Agency of Sweden in collaboration with the region of Västra Götaland (i.e. Skaraborg, Älvsborg and Bohus county councils and parts of the City of Göteborg) and Statistics Sweden [41]. The national survey has been conducted annually since 2004, with additional samples for Västra Götaland in 2007, 2011 and 2015. The sample consisted of a random selection of individuals from age 16 to 84 from Västra Götaland. The participants answered a self-administered questionnaire covering areas such as health and well-being, health care, living habits, work and psychosocial working conditions, and social relationships. Data collection was conducted by mailed surveys with the option to answer via a web-based form. Register data from Statistics Sweden was also collected to assess age, gender, civil status, education, country of birth and citizenship.

In this study, pooled data was used from survey years 2011 and 2015. The response rate was 54.4\% $(n=41,740)$ in 2011 and 55.5\% $(n=52,348)$ in 2015. The majority of dropouts were registered as mail returns, while only a small fraction were due to not wanting to participate, questionnaire problems or inability to contact participants $[41,42]$. Due to the exclusion of the non-working age population (i.e. younger than 18 and older than 65) the final sample of the pooled dataset was $n=71,643$, of whom $7.9 \%$ (men $n=2581$ and women $n=3099$ ) were born outside Sweden.

\section{Measurements \\ Psychological distress}

Psychological distress was measured by the 12 -item version of the General Health Questionnaire (GHQ-12) which has been previously used in studies of migration and mental health $[13,43]$. It is a well-validated screening instrument developed to assess non-psychotic mental illness, typically depressiveness and anxiety [44]. The participants were asked about their feelings and abilities during the last few weeks, such as enjoying day-to-day activities, being able to concentrate, making decisions, overcoming difficulties and problems, having sleeping difficulties, feeling unhappy, depressed, and losing confidence and self-worth [44]. The severity of each item was measured using a 4-point scale, dichotomised into 'better than usual/as usual' and 'worse than usual/much worse than usual'. In accordance with a Swedish validation study [44], the items were summed into a 12 point summary index and then dichotomised, with three or more symptoms coded as having psychological distress.

\section{Migration}

Country of birth was obtained through the Total Population Register, and reported as origin from Africa, Asia, Europe (excluding the Nordic countries), North America, the Nordic countries (excluding Sweden), Oceania, Sweden and South America. The variable was then coded into people born in Sweden (referred to as natives) and those not born in Sweden (migrants). The group of migrants were then further categorised by region of origin; into Nordic countries, European countries (excluding Nordic countries), and non-European countries (i.e., Africa, Asia, Oceania, and North America and South America).

\section{Social integration measures}

The explanatory variables were selected in correspondence with previous research to capture the complex multidimensional process of social integration [10-14, 34]. An overview of all variables is shown in Table 1. All items were based on self-reported data, if not stated otherwise.

Three different aspects of labour market integration were assessed; current labour market position, psychosocial working conditions and economic disparities. Labour market position was measured with 12 different position choices, which were then categorised into three groups: (1) employed/self-employed (reference), (2) unemployed/labour market measure, and (3) outside the labour market (including leave of absence or parental leave, studying or training, taking care of one's household, sickness benefits, disability pension, and long term sick leave (more than 3 months)). Early retirements and written answers of other employment positions were 
Table 1 Descriptive characteristics of native-born and foreign-born (origin from Nordic-, European- and non-European countries) in working age population (18-65 yrs.)

\begin{tabular}{|c|c|c|c|c|c|c|c|c|c|c|c|c|c|c|}
\hline & \multicolumn{2}{|c|}{$\begin{array}{l}\text { Native-born } \\
(n=65,963)\end{array}$} & \multicolumn{2}{|c|}{$\begin{array}{l}\text { Foreign-born } \\
(n=5680)\end{array}$} & \multirow[b]{2}{*}{$p$} & \multicolumn{3}{|c|}{$\begin{array}{l}\text { Nordic } \\
(n=1589)\end{array}$} & \multicolumn{3}{|c|}{$\begin{array}{l}\text { European } \\
(n=2175)\end{array}$} & \multicolumn{3}{|c|}{$\begin{array}{l}\text { Non-European } \\
(n=1874)\end{array}$} \\
\hline & $\%$ & $(n=)$ & $\%$ & $(n=)$ & & $\%$ & $(n=)$ & $p$ & $\%$ & $(n=)$ & $p$ & $\%$ & $(n=)$ & \\
\hline Survey (2011) & 49.2 & (32478) & 73.4 & $(4167)$ & * & 71.2 & $(1132)$ & ${ }^{*}$ & 73.7 & $(1602)$ & ${ }^{*}$ & 75.7 & $(1418)$ & \\
\hline Men & 44.7 & (29493) & 45.4 & $(2581)$ & & 42.3 & (672) & & 45.8 & (996) & & 47.3 & (887) & \\
\hline Married/cohabiting civil status & 75.1 & (49506) & 81.0 & $(4603)$ & * & 74.1 & $(1176)$ & & 81.8 & $(1780)$ & * & 86.1 & $(1614)$ & \\
\hline Age, mean (sd) & 45.3 & $(13.8)$ & 44.5 & $(13.1)$ & * & 52.6 & $(11.1)$ & * & 43.7 & $(12.9)$ & * & 39.5 & $(12.3)$ & \\
\hline Blue-collar occupational class & 48.0 & (31539) & 61.4 & (3236) & * & 55.8 & (880) & * & 58.0 & $(1234)$ & * & 70.4 & $(1300)$ & \\
\hline Compulsory education & 15.9 & (10424) & 21.7 & $(1136)$ & * & 24.8 & (372) & * & 14.0 & (286) & * & 28.4 & $(474)$ & \\
\hline Secondary education & 54.4 & (35710) & 44.3 & $(2321)$ & & 52.1 & (780) & & 44.8 & (917) & & 36.8 & (615) & \\
\hline Post-secondary education & 29.8 & (19550) & 34.1 & $(1785)$ & & 23.1 & (346) & & 41.2 & (844) & & 34.9 & (583) & \\
\hline \multicolumn{14}{|l|}{ Disposable income, mean (sd) ${ }^{b}$} & \\
\hline Q 1 & 48.1 & $(61.4)$ & 43.6 & $(43.1)$ & * & 30.6 & $(47.8)$ & * & 45.0 & $(39.8)$ & * & 49.0 & $(42.7)$ & \\
\hline Q 2 & 142.4 & $(15.1)$ & 139.9 & $(15.2)$ & & 141.7 & $(15.4)$ & & 139.9 & $(15.1)$ & & 138.6 & $(15.2)$ & \\
\hline Q 3 & 197.7 & $(15.8)$ & 195.7 & $(15.5)$ & & 196.0 & $(15.8)$ & & 195.3 & $(15.4)$ & & 195.6 & $(15.4)$ & \\
\hline Q 4 & 253.9 & $(18.8)$ & 252.6 & $(18.5)$ & & 252.9 & $(18.4)$ & & 252.8 & $(18.9)$ & & 251.8 & $(18.6)$ & \\
\hline Q 5 & 422.8 & $(1471.0)$ & 340.0 & $(256.0)$ & & 387.4 & $(180.9)$ & & 403.1 & $(238.2)$ & & 421.2 & $(314.2)$ & \\
\hline Employed/Self-employed & 74.8 & $(46820)$ & 57.6 & (3024) & * & 66.3 & $(961)$ & * & 63.1 & $(1290)$ & * & 44.1 & (757) & \\
\hline Unemployed/Labour market practice & 4.2 & $(2648)$ & 11.0 & $(576)$ & & 5.3 & (77) & & 9.4 & (193) & & 17.6 & (302) & \\
\hline Outside the labour market $^{a}$ & 20.9 & (13105) & 31.4 & $(1651)$ & & 28.4 & (412) & & 27.5 & (561) & & 38.3 & $(657)$ & \\
\hline Low support from co-workers & 6.8 & $(4502)$ & 11.4 & (649) & * & 6.4 & $(102)$ & & 10.8 & (235) & ${ }^{*}$ & 16.1 & (301) & \\
\hline Low support from manager & 8.6 & $(5576)$ & 10.1 & (573) & * & 7.2 & (114) & & 9.9 & (215) & * & 12.8 & (239) & \\
\hline Low job satisfaction & 10.1 & $(6676)$ & 12.4 & $(702)$ & * & 10.4 & (165) & & 12.5 & (272) & ${ }^{*}$ & 13.7 & (256) & \\
\hline Difficulty making ends meet & 12.7 & $(8325)$ & 23.6 & $(1315)$ & * & 18.8 & (295) & * & 20.8 & (445) & * & 30.8 & $(561)$ & \\
\hline Low cash margin & 14.9 & (9793) & 35.1 & (1953) & * & 22.4 & (352) & * & 29.0 & (620) & * & 52.7 & (961) & \\
\hline Being socially active, mean (sd) & 4.0 & $(2.3)$ & 2.8 & $(2.3)$ & * & 3.0 & $(2.2)$ & * & 3.1 & $(2.4)$ & * & 2.2 & $(2.1)$ & \\
\hline Low social support & 9.9 & $(6448)$ & 18.5 & $(1025)$ & * & 15.6 & (245) & * & 14.9 & (316) & * & 25.2 & (455) & \\
\hline Low practical support & 3.6 & $(2333)$ & 12.2 & $(684)$ & . & 8.8 & (139) & * & 9.7 & (208) & * & 18.1 & (331) & \\
\hline Low trust in others & 22.1 & (14446) & 40.0 & $(2212)$ & * & 28.6 & $(450)$ & * & 42.1 & (892) & * & 46.9 & (852) & \\
\hline Experiences of discrimination & 19.8 & (12972) & 21.7 & $(1212)$ & * & 19.0 & (299) & & 22.5 & $(480)$ & ${ }^{*}$ & 22.9 & (421) & \\
\hline
\end{tabular}

"denotes a $p$-value $<0.05$ between native-born and foreign-born; and separately between native-born and (1) Nordic, (2) European, and (3) non-European.

Pearson's chi-square and T-test

aLeave of absence, parental leave, taking care of one's household, studying, training, disability pension, sickness benefits and long term sick leave

${ }^{b}$ Disposable income is shown in thousand (tkr) Swedish kronor (SEK) within quintile (Q) 1-5

excluded. Economic disparities were measured with variables that assessed participants' financial strain, i.e. problems managing ongoing expenses, such as food, rent and bills during the past 12 months (no, one time or several occasions, dichotomised into yes or no) and low cash margin, i.e. inability to obtain 15,000 SEK (approx. 1600 EUR) in 1 week for an unforeseen situation (yes or no). Participants' psychosocial working conditions were measured by three variables. The first two asked if the participants felt support and assistance from their colleagues and closest manager (4-point scale, dichotomised into 'yes, mostly/to some extent' and 'no/do not know/ do not have a manager'). The third variable asked whether the participants were satisfied with their working duties (5-point scale, dichotomised into 'very satisfied /fairly satisfied' and 'neither satisfied nor unsatisfied/ fairly unsatisfied/very unsatisfied').

Social connections and networks were measured with items that assessed level of social activity, social- and practical support, and general trust in others. Social activity during the last 12 months was measured by assessing participation in 15 different activities, in areas such as courses and study circles, culture and sports events, political engagements, gatherings with family and friends and social networks online. The items (each with the response option yes or no) were added into a continuous 
index ranging from low to high social activity (0-15). Social support and practical support asked if participants had someone to share their inner feelings with (yes or no), and if they could receive practical help when needed (5-point scale, dichotomised into 'yes/always or often' and 'no/never or mostly'). Trust in others asked if participants generally trusted other people (yes or no).

Discrimination experiences were assessed with an item that inquired if the participants had been treated unfairly or violated in the last 3 months (on a 3-point scale, dichotomised into yes, often/seldom or no). Participants were also asked if they could determine the reason for discrimination (such as ethnicity, religion, skin colour and appearance) but due to lack of impact, we only included general experiences of discrimination in the final models.

Six different items measured sociodemographic factors, based on register data. Participants' age and gender measured as age during year of data collection (18 to 65 years old), and 'men' or 'women'. Occupational class was based on Statistics Sweden's socioeconomic classification [45] and coded into 'blue-collar workers' (unskilled manual workers and skilled manual workers) and 'white-collar workers' (assistant non-manual, intermediate non-manual, self-employed and other). Income was assessed using individual disposable income and coded into five quintiles. Education was coded as 'compulsory education', 'secondary education' and 'post-secondary education'. Civil status was based on both register data and self-reported data of cohabiting living arrangements. The civil status variables were coded into 'married/cohabiting' and 'unmarried/not cohabiting' (including divorced and widow/widower).

\section{Analysis}

Descriptive statistics were calculated with Pearson's chi-square and t-tests to assess statistical differences between natives and migrants within the total sample, and between the migrant sub-samples by region of origin. The main analysis comprised a Blinder-Oaxaca decomposition for non-linear regression models [46, 47], with the aim to decompose the difference in mean psychological distress between natives and migrants across a set of explanatory factors. This is a data driven, explorative technique that enables us to assess multiple factors inherent in the complex phenomenon of social integration that can subsequently influence mental health. The method's ability to quantify both the absolute and relative explained parts of inequalities has resulted in its increasing utilisation within fields such as gender-based income inequalities and socioeconomic health inequalities [47-50].

The analysis was conducted in two steps across four different paired groups; 1 ) between the native-born and all migrants in the total sample, and then between the native-born and migrants from 2) Nordic countries, 3) European countries and 4) non-European countries (using natives as reference category in each analysis). In the first step, the mean difference in psychological distress between each pair was calculated, while also taking into account group differences in the explanatory variables. In the second step, we estimated the magnitude of the health gap that could be explained by the observed group difference, and a detailed decomposition was applied to display each explanatory variable's relative contribution to the health gap [51]. Positive values are interpreted as the average health improvement that could be expected in migrants if they had the same predicted values for the explanatory variables as the native-born. Negative values are instead interpreted as the potential increase in the mental health inequality between the paired groups. The latter is typically found when a factor that promotes health is over-represented in the advantaged group (e.g., a higher proportion of employment in the native-born) and is also related to factors which can negatively influence health among the disadvantaged group (e.g., a higher prevalence of educational mismatch or poor psychosocial working conditions in migrant groups) [52].

Estimations were reported as log odds and as the share of the relative contribution (presented as a percentage of the total explained contribution) of each explanatory variable to the mental health inequalities. The analyses were conducted in Stata 14, with the Oaxaca command (and the options of logit for non-linear decompositions, pooled model for group coefficients and $v c r$ with 50 repetitions to estimate 95\% Confidence Intervals). Survey year was also included in all analyses to adjust for potential calendar effects.

\section{Results}

Descriptive statistics are presented in Table 1, showing that native-born persons on average had higher rates of employment and better psychosocial working conditions, fewer social and economic disadvantages and fewer experiences of discrimination than migrants. Similar social and economic patterns were found when dividing the foreign-born into Nordic, European and non-European groups, with Nordic migrants having the best outcomes among the foreign-born, followed by European and non-European migrants.

Psychological distress was also found to be more prevalent among migrants compared to natives (see Table 2). As a whole, the mean psychological distress score was 0.07 higher among migrants compared to natives $(\mathrm{p}<0.05)$. When decomposing the mental health inequality, the most important explanatory social integration factor was social activity $(0.014, \mathrm{p}<0.05$, corresponding to $20 \%$ of the health gap). This finding can be interpreted as the expected 
Table 2 Non-linear Oaxaca decomposition of mental health (GHQ) gap between native-born and foreign-born in Sweden

\begin{tabular}{|c|c|c|}
\hline GHQ foreign-born, mean $(=n)$ & .38 & $(4496)$ \\
\hline GHQ native-born, mean $(=n)$ & .31 & $(60681)$ \\
\hline Difference in GHQ & \multicolumn{2}{|l|}{$.07^{*}$} \\
\hline Explanatory variables & \multicolumn{2}{|c|}{$\begin{array}{c}\text { Contribution to explained } \\
\text { health gap (\%) }\end{array}$} \\
\hline \multicolumn{3}{|l|}{ Labour market position $^{\text {a }}$} \\
\hline Unemployed & $.007^{*}$ & $10 \%$ \\
\hline Outside the labour market & $.011^{*}$ & $15 \%$ \\
\hline \multicolumn{3}{|l|}{ Economic hardship } \\
\hline Difficulty making ends meet & $.012^{*}$ & $16 \%$ \\
\hline Low cash margin & $.006^{*}$ & $8 \%$ \\
\hline \multicolumn{3}{|l|}{ Psychosocial working conditions } \\
\hline Lack of support from co-workers & -.000 & $0 \%$ \\
\hline Lack of support from manager & $.000^{*}$ & $1 \%$ \\
\hline Low job satisfaction & $.005^{*}$ & $7 \%$ \\
\hline \multicolumn{3}{|l|}{ Social relations } \\
\hline Low social activity & $.014^{*}$ & $20 \%$ \\
\hline Low social support & $.012^{*}$ & $16 \%$ \\
\hline Low practical support & $.005^{*}$ & $7 \%$ \\
\hline Low trust in others & $.012^{*}$ & $17 \%$ \\
\hline Experiences of discrimination & $.006^{*}$ & $8 \%$ \\
\hline \multicolumn{3}{|l|}{ Sociodemographic characteristics ${ }^{\text {a }}$} \\
\hline Women & -.000 & $0 \%$ \\
\hline Married/cohabiting & $.001^{*}$ & $1 \%$ \\
\hline Age & .000 & $0 \%$ \\
\hline Blue-collar occupational class & $-.001^{*}$ & $-1 \%$ \\
\hline Income & .000 & $0 \%$ \\
\hline \multicolumn{3}{|l|}{ Education } \\
\hline Secondary education & -.001 & $-1 \%$ \\
\hline Post-secondary education & $.001^{*}$ & $2 \%$ \\
\hline
\end{tabular}

The results are presented as log odds (\%). The relative contribution of each explanatory variables was calculated as the share (\%) of the total difference in psychological distress

"denotes $p<0.05$

a employed, men, not married or cohabiting, white-collar occupational class, compulsory education as reference categories

mental health improvement among migrants if they had similar opportunities to engage in social activities as natives, which would decrease the mental health gap by $20 \%$. Other important contributions were low trust in others (17\%), financial strain (16\%), low degree of social support (16\%) and being outside the labour market $(15 \%)$ or unemployed (10\%). Having a low cash margin, low job satisfaction, lack of practical support and experiencing discrimination made smaller contributions (7-8\%). Psychosocial working conditions and sociodemographic factors made low or non-significant contributions to the difference in psychological distress between natives and migrants. The findings further indicated that the total contribution of the social integration explanatory factors summed up to more than $100 \%$ (data not shown in table), suggesting that the mental health gap found was mainly due to within-group differences, thus highlighting the important influence of within-group variance.

When dividing migrants by Nordic, European and non-European origin, a slightly different pattern was observed (see Table 3). Persons of Nordic origin reported on average a 0.05 higher psychological distress score compared to native-born persons $(p<0.05)$, whereas European and non-European populations reported psychological distress scores that were 0.08 higher than the native-born $(\mathrm{p}<0.05)$. In analyses comparing natives and the Nordic population, lack of social activity (28\%), social support (19\%), being outside the labour market (18\%) and financial strain (16\%) were the largest explanatory factors that contributed to the mental health gap. Given equitable social integration in terms of social support, social engagements and paid employment, the mental health gap between natives and those of Nordic origin would be expected to decrease by around $80 \%$. Other important factors were low trust in others, low practical support, age, sex, low cash margin and unemployment (4-11\%).

The mental health gap between the native-born and European-born populations was largely explained by low trust in others (17\%), low social activity (13\%), difficulty making ends meet (11\%), lack of social support (9\%) and experiencing discrimination (9\%). Factors that made significant but smaller contributions were being outside the labour market or unemployed, low job satisfaction, lack of practical support and having a post-secondary education (4-8\%). Analyses comparing the native-born and non-European populations indicated that low participation in social activities (22\%), low social support (22\%), economic hardship (21 and 12\%), low trust in others (19\%), unemployment (19\%) and being outside the labour market (17\%) all made significant contributions to the mental health gap between these groups. Discrimination and lack of practical support each explained 10\% of the health gap. The findings further indicated that being older and having a white-collar occupational class increased the health gap between groups; these factors were more prevalent among the native-born and were also related to poor mental health among the non-European population.

\section{Discussion}

In the present study, we assessed for mental health inequalities between natives and different groups of migrants in Sweden, and examined the extent to which different social integration factors contributed to these inequalities. The findings showed that psychological 
Table 3 Decomposing mental health gap between native-born and Nordic-, European- and non-European persons in Sweden

\begin{tabular}{|c|c|c|c|c|c|c|}
\hline \multirow[b]{2}{*}{ GHQ foreign-born, mean (=n) } & \multicolumn{2}{|l|}{ Nordic } & \multicolumn{2}{|c|}{ European } & \multicolumn{2}{|c|}{ non-European } \\
\hline & .35 & $(1321)$ & .39 & $(1763)$ & .39 & (1388) \\
\hline GHQ native-born, mean $(=\mathrm{n})$ & .31 & $(60681)$ & .31 & $(60681)$ & .31 & $(60681)$ \\
\hline Difference in GHQ & \multicolumn{2}{|l|}{$.05^{*}$} & \multicolumn{2}{|l|}{$.08^{*}$} & \multicolumn{2}{|l|}{$.08^{*}$} \\
\hline Explanatory variables & \multicolumn{2}{|c|}{$\begin{array}{l}\text { Contribution to explained health } \\
\text { gap (\%) }\end{array}$} & \multicolumn{2}{|c|}{$\begin{array}{l}\text { Contribution to explained health } \\
\text { gap (\%) }\end{array}$} & \multicolumn{2}{|c|}{$\begin{array}{l}\text { Contribution to explained health } \\
\text { gap (\%) }\end{array}$} \\
\hline \multicolumn{7}{|c|}{ Labour market position (Employed as reference) } \\
\hline Unemployed & $.002^{*}$ & $4 \%$ & $.005^{*}$ & $6 \%$ & $.014^{*}$ & $17 \%$ \\
\hline Outside the labour market & $.008^{*}$ & $18 \%$ & $.007^{*}$ & $8 \%$ & $.016^{*}$ & $19 \%$ \\
\hline \multicolumn{7}{|l|}{ Economic hardship } \\
\hline Difficulty making ends meet & $.007^{*}$ & $16 \%$ & $.009^{*}$ & $11 \%$ & $.018^{*}$ & $21 \%$ \\
\hline Low cash margin & $.003^{*}$ & $6 \%$ & $.004^{*}$ & $5 \%$ & $.010^{*}$ & $12 \%$ \\
\hline \multicolumn{7}{|l|}{ Psychosocial working conditions } \\
\hline Lack of support from co-workers & .000 & $0 \%$ & .000 & $0 \%$ & -.000 & $0 \%$ \\
\hline Lack of support from manager & -.001 & $-1 \%$ & .000 & $0 \%$ & $.001^{*}$ & $1 \%$ \\
\hline Low job satisfaction & .001 & $3 \%$ & $.006^{*}$ & $7 \%$ & $.006^{*}$ & $7 \%$ \\
\hline \multicolumn{7}{|l|}{ Social relations } \\
\hline Low social activity & $.013^{*}$ & $28 \%$ & $.011^{*}$ & $13 \%$ & $.019^{*}$ & $22 \%$ \\
\hline Low social support & $.009^{*}$ & $19 \%$ & $.008^{*}$ & $9 \%$ & $.019^{*}$ & $22 \%$ \\
\hline Low practical support & $.003^{*}$ & $7 \%$ & $.005^{*}$ & $5 \%$ & $.009^{*}$ & $10 \%$ \\
\hline Low trust in others & $.005^{*}$ & $11 \%$ & $.015^{*}$ & $17 \%$ & $.016^{*}$ & $19 \%$ \\
\hline Experiences of discrimination & -.000 & $-1 \%$ & $.007^{*}$ & $9 \%$ & $.008^{*}$ & $10 \%$ \\
\hline \multicolumn{7}{|l|}{ Sociodemographic characteristics } \\
\hline Sex (men as reference) & $.002^{*}$ & $4 \%$ & -.001 & $-1 \%$ & -.001 & $-2 \%$ \\
\hline Married/cohabiting & .000 & $0 \%$ & $.001^{*}$ & $1 \%$ & $.001^{*}$ & $1 \%$ \\
\hline Age & $.005^{*}$ & $10 \%$ & $-.001^{*}$ & $-1 \%$ & $-.003^{*}$ & $-4 \%$ \\
\hline Occupational class & -.001 & $-1 \%$ & -.001 & $-1 \%$ & $-.002^{*}$ & $-2 \%$ \\
\hline Income & .000 & $0 \%$ & .000 & $0 \%$ & .000 & $0 \%$ \\
\hline \multicolumn{7}{|l|}{ Compulsory education } \\
\hline Secondary education & -.000 & $0 \%$ & -.000 & $0 \%$ & -.001 & $-1 \%$ \\
\hline Post-secondary education & $-.002^{*}$ & $-4 \%$ & $.003^{*}$ & $4 \%$ & $.001^{*}$ & $2 \%$ \\
\hline
\end{tabular}

Non-linear Oaxaca decomposition presented as log odds (\%)). The relative contribution of each explanatory variable was calculated as the share (\%) of the total difference in psychological distress

*denotes $p<0.05$

distress was significantly more common among migrants from Nordic-, European- and non-European countries than among natives. Our findings further indicated that the predominant social integration indicators explaining the mental health inequalities were financial strain, lack of social activity and low social support. In stratified analyses, being unemployed and outside the labour market were also identified as important factors explaining the health gap between natives and the Nordic and non-European populations, while low trust in others and discrimination contributed to this gap in the European and non-European populations.

Prior research has demonstrated associations between poor mental health and different aspects of social integration [10, 11, 24, 32, 53], although only a paucity have used a multidimensional approach such as ours [32], which allows for a more holistic assessment of the relationship between social integration and mental health. Compared to the evidence on labour market integration $[24,53]$, previous public health research has paid less attention to social connections and networks, as well as the complex interplay between economic and social resources in social integration. Research on social relationships and health has shown that having access to social networks and social support decreases stress and buffers against mental ill health [8]. This may be of particular relevance for migrants, who typically have fewer friends and family in the host country and therefore also 
often have less access to social arenas than natives [10, 30]. Findings from this study emphasise that even when taking labour market factors into account, social connections and networks remained an important determinant of mental health inequality. In fact, lack of social support and engagement in social activities explained about one third of the mental health inequality between natives and migrants, and approximately $40 \%$ of the health gap between natives and Nordic and non-European migrants, respectively. Lack of practical and social support among migrants may entail a lack of social ties in everyday life, leading to feelings of social instability, social isolation or lack of belonging in the new society, which can negatively influence ability to adapt and cope with a new social environment and mental health [3, 31]. Conversely, participation in social and sports activities could buffer against mental ill health by increasing trust in other people. This in turn may facilitate cultural adaptation and coping abilities to handle post-migration stressors, such as discrimination, thereby also serving as a protective factor against poor mental health [11, 32]. This study therefore stresses the importance of social connections as a key component in migrants' social integration and a determinant of migrant mental health. In addition, given the lack of studies that have simultaneously assessed labour market and social connectivity aspects of integration, the persistence of lack of social relations as a key contributor to mental health inequalities between natives and migrants might also suggest that lack of social network is an overlooked component of unemployment that may be particularly important for mental health; however, further studies are needed to assess this possibility.

Our findings are in line with previous research suggesting that financial strain is a key risk factor for poor mental health among migrants $[24,53]$. This relationship persisted even after accounting for unemployment, being outside the labour market, psychosocial working conditions and sociodemographic factors. Financial hardships may have a stronger influence on mental health among persons of foreign-origin than among natives for several reasons. First, migrants may experience such hardships to a greater degree than natives due to delayed post-migration labour market entry and lower average earned wages than natives [54]. Migrants also tend to face greater insecurity in the labour market, which may result in periods of unemployment and resulting financial strain. In fact, prior studies have suggested that it can take up to 10 years before migrants in Sweden experience living conditions equal to those of the native-born [55]. Migrants may also lack the professional social networks available to natives that could assist with social mobility. In addition, many migrants send remittances to family members or friends in the country of origin [56] which entails less disposable income available in the country of residence. As such, migrants may continue to experience financial difficulties for extended periods post-migration. Persistent financial hardships may be one important contributing factor to the growing income inequality in Sweden [57] as well as the creation of marginalized groups characterized by economic hardship and ill health.

Although experiences of discrimination have previously been associated with poorer self-rated health and mental ill health, as well as poorer social integration $[2,36,37]$, in the current study discrimination had a lower impact on the mental health inequality between migrants and natives than economic or other social aspects of integration. However, experiences of discrimination are likely to interact with other experiences of social and material adversity, such as social isolation and financial strain $[58,59]$, which similarly influence social integration and mental ill health. Further research is therefore needed to explore the combined influence of these factors on mental health.

\section{Limitations}

This study contributes novel insights describing the extent to which different aspects of social integration can explain mental health inequalities between natives and different migrant groups in Sweden. Preforming such analysis requires rich and comprehensive data, such as the HET-surveys, which contain reliable self-reported and register based data compiled by Statistics Sweden [41]. However, one limitation of our research is the cross-sectional study design, which prevents us from making any causal inferences or controlling for previous health status. Another potential issue with self-reported data is the generally low response-rate in surveys and potential response-bias. That is, people with relatively poor health and lower levels of social integration may be more likely to decline participation in research studies, suggesting that the mental health disparities found in this study may be underestimated. However, the data collection and sensitivity analysis conducted by Statistics Sweden showed no systematic patterns in participant dropout rates, supporting the reliability of the findings.

The register-based measure of country of origin used in this study has the strength of having relatively high reliability in comparison with self-reported reason for migration, which has a greater potential for misclassification bias $[60,61]$. However, we were unable to control for other factors that may influence social integration, such as language skills, neighbourhood segregation, as well as the nativity of the parents or grandparents of the native-born, which could bias our findings. The inability to 
account for the migration background of the native-born could entail that the mental health gap between the nativeand foreign-born is even larger than estimated in the current [62]. Consequently, due to the complexity of capturing the multi-dimensional phenomenon of social integration, our findings should be interpreted with caution.

A limitation related to the non-linear Oaxaca-Blinder decomposition used in this study is the sensitivity to the reference group and the imputation order of explanatory variables [49], which can potentially influence the results. However, the selection of the foreign-born as the more socially and materially disadvantaged group has empirical support $[10,23,30]$. Robustness of the results was also tested using random imputation of variables into the models.

\section{Conclusion and policy implications}

This study quantified the extent to which different aspects of social integration may explain mental health inequalities between natives and migrants in Sweden. Multiple aspects of social integration appeared to play a central role in affecting mental health among migrants in Sweden, with financial strain, social relations, and civic engagement standing out as the most important aspects of social integration. Among Nordic and non-European migrants, lack of labour market participation was identified as a particular barrier for social integration and mental health, while lack of trust and discrimination had an adverse effect on European and non-European migrants' health and social integration. Future research and public health works should give greater consideration to migrants' social networks and social support, which this study suggests may be just as important as labour market integration in influencing migrants' mental health. Despite Sweden's historically generous migration and integration polices, native-migrant inequalities in mental health were observed in the current study, particularly among migrants from non-European countries. However, the data for this study was conducted before the 2016 implementation of increasingly restrictive entry, right to residence, and integration policies in Sweden, which were a response to the large number of refugees and asylum seekers that arrived in the country in 2015. This development, in conjunction with an increasingly flexible and polarized labour market, suggests that newly arrived migrants may face increasing resettlement and integration difficulties, potentially leading to more severe mental health inequities between the native- and foreign-born.

\section{Abbreviations}

GHQ: General Health Questionnaire; HET: Health on Equal Terms

\section{Acknowledgements}

The authors would like thank the county council of Västra Götaland (Skaraborg, Älvsborg and Bohus county councils and parts of the city of
Göteborg) for giving us access to the Health on Equal Terms surveys from 2011 and 2015.

\section{Funding}

This study was funded by the Swedish Research Council for Health, Working Life and Welfare (Forte, grant no. 2016-07128). The funding body had no further involvement in the research process.

\section{Availability of data and materials}

The data that support the findings of this study are available from the Västra Götaland County Council but these data and not publicly available. However, data are available from the authors upon reasonable request and with permission of the Västra Götaland County Council.

\section{Authors' contributions}

$A B, M R$ and $A D$ conceived the theoretical framework of the manuscript. $A B$ conceived and designed the methodological framework, drafted the manuscript and carried out the statistical analyses. All authors participated in results interpretation and revision of the manuscript. All authors have read and approved of the final version.

Ethics approval and consent to participate

Ethical approval to conduct the study was granted by the Stockholm Regional Ethical Review Board (approval no. 2017/716-31). All participants in the survey have given informed consent for the data to be used for research purposes.

Consent for publication

Not applicable.

\section{Competing interests}

The authors declare that they have no competing interests.

\section{Publisher's Note}

Springer Nature remains neutral with regard to jurisdictional claims in published maps and institutional affiliations.

Received: 4 December 2018 Accepted: 11 March 2019

Published online: 03 April 2019

References

1. Public Health Agency of Sweden. Folkhälsans utveckling - Årsrapport 2018 [Public Health Development - Annual Report 2018]. 2018.

2. Bhugra D. Migration and mental health. Acta Psychiatr Scand. 2004;109(4): 243-58.

3. Alegría M, Álvarez K, DiMarzio K. Immigration and mental health. Curr Epidemiol Rep. 2017:4(2):145-55.

4. Priebe S, Giacco D, El-Nagib R. Public health aspects of mental health among migrants and refugees: a review of the evidence on mental health care for refugees, asylum seekers and irregular migrants in the WHO European region. Copenhagen: World Health Organization, Regional Office for Europe; 2016.

5. United Nations. Programme of action of the world summit for social development. World summit for social development. Copenhagen: United Nations; 1995

6. Bhui K, Lawrence A, Klineberg E, Woodley-Jones D, Taylor S, Stansfeld S, et al. Acculturation and health status among African-Caribbean, Bangladeshi and White British adolescents. Soc Psychiatry Psychiatr Epidemiol. 2005; 40(4):259-66.

7. Bhugra D, Becker MA. Migration, cultural bereavement and cultural identity. World Psychiatry. 2005;4(1):18.

8. Butler M, Warfa N, Khatib Y, Bhui K. Migration and common mental disorder: an improvement in mental health over time? Int Rev Psychiatry. 2015;27(1): 51-63.

9. Chen W, Ling L, Renzaho AM. Building a new life in Australia: an analysis of the first wave of the longitudinal study of humanitarian migrants in Australia to assess the association between social integration and self-rated health. BMJ Open. 2017;7(3):e014313.

10. Johnson CM, Rostila M, Svensson AC, Engström K. The role of social capital in explaining mental health inequalities between immigrants and Swedish- 
born: a population-based cross-sectional study. BMC Public Health. 2017; 17(1):117.

11. Lecerof SS, Stafström M, Westerling R, Östergren P-O. Does social capital protect mental health among migrants in Sweden? Health Promot Int. 2015; 31(3):644-52.

12. Rostila M. Birds of a feather flock together-and fall ill? Migrant homophily and health in Sweden. Sociol Health IIIn. 2010;32(3):382-99.

13. Sidorchuk A, Engström K, Johnson CM, Leeoza NK, Möller J. Employment status and psychological distress in a population-based cross-sectional study in Sweden: the impact of migration. BMJ Open. 2017;7(4):e014698.

14. Dalgard OS, Thapa SB. Immigration, social integration and mental health in Norway, with focus on gender differences. Clin Pract Epidemiol Ment Health. 2007;3(1):24.

15. Statistics Sweden. Population statistics in summary 1960-2018. 2019. Avalible at: https://www.scb.se/hitta-statistik/statistik-efter-amne/befolkning/ befolkningens-sammansattning/befolkningsstatistik/pong/tabell-ochdiagram/helarsstatistik-riket/befolkningsstatistik-i-sammandrag/. Accessed 16 Mar 2019.

16. Juárez SP, Drefahl S, Dunlavy A, Rostila M. All-cause mortality, age at arrival, and duration of residence among adult migrants in Sweden: a populationbased longitudinal study. SSM-Popul Health. 2018;6:16.

17. Dunlavy AC, Rostila M. Health inequalities among workers with a foreign background in Sweden: do working conditions matter? Int J Environ Res Public Health. 2013;10(7):2871-87.

18. Lindström M, Sundquist J, Östergren P-O. Ethnic differences in self reported health in Malmö in southern Sweden. J Epidemiol Community Health. 2001; 55(2):97-103.

19. Sundquist J, Johansson S-E. Long-term illness among indigenous and foreign-born people in Sweden. Soc Sci Med. 1997;44(2):189-98.

20. Graham H. Unequal lives: health and socioeconomic inequalities. UK: McGraw-Hill Education; 2007.

21. Jahoda M. Work, employment, and unemployment - values, theories, and approaches in social-research. Am Psychol. 1981;36(2):184-91.

22. Statistics Sweden. 2017. Labour Force Surveys (LFS) 2016, Avalible at: https://www.scb.se/contentassets/5a6d6bf5609f42b3ba5d4f02bc255dc2/ am0401_2016a01_sm_am12sm1701.pdf. Accessed 16 Mar 2019.

23. Dunlavy A, Rostila M. Arbetsmiljön bland utrikesfödda anställda i Sverige. Arbetsmarknad Arbetsliv. 2017;23(1):44-63.

24. Hollander AC, Bruce D, Ekberg J, Burstrom B, Ekblad S. Hospitalisation for depressive disorder following unemployment--differentials by gender and immigrant status: a population-based cohort study in Sweden. J Epidemiol Community Health. 2013;67(10):875-81.

25. Setia MS, Quesnel-Vallee A, Abrahamowicz M, Tousignant P, Lynch J. Different outcomes for different health measures in immigrants: evidence from a longitudinal analysis of the National Population Health Survey (1994-2006). J Immigr Minor Health. 2012;14(1):156-65.

26. Lerner Y, Kertes J, Zilber N. Immigrants from the former Soviet Union, 5 years post-immigration to Israel: adaptation and risk factors for psychological distress. Psychol Med. 2005;35(12):1805-14.

27. Paul Kl, Moser K. Unemployment impairs mental health: meta-analyses. $J$ Vocat Behav. 2009;74(3):264-82

28. McKee-Ryan FM, Song ZL, Wanberg CR, Kinicki AJ. Psychological and physical well-being during unemployment: a meta-analytic study. J Appl Psychol. 2005;90(1):53-76.

29. Strandh M, Winefield A, Nilsson K, Hammarstrom A. Unemployment and menta health scarring during the life course. Eur J Pub Health. 2014;24(3):440-5.

30. Rostila M. Social capital and health in the Swedish welfare state. Health inequalities and welfare resources: continuity and change in Sweden; 2007. p. 157-77.

31. Diderichsen F, Evans T, Whitehead M. The social basis of disparities in health. Challenging inequities in health: from ethics to action, vol. 1; 2001. p. 12-23.

32. Lin Y, Zhang Q, Chen W, Ling L. The social income inequality, social integration and health status of internal migrants in China. Int J Equity Health. 2017;16(1):139.

33. Umberson D, Karas Montez J. Social relationships and health: a flashpoint for health policy. J Health Soc Behav. 2010;51(1_suppl):S54-66.

34. Ager A, Strang A. Understanding integration: a conceptual framework. J Refug Stud. 2008;21(2):166-91.

35. Singh-Manoux A, Adler NE, Marmot MG. Subjective social status: its determinants and its association with measures of ill-health in the Whitehall II study. Soc Sci Med. 2003;56(6):1321-33.
36. Chou K-L. Perceived discrimination and depression among new migrants to Hong Kong: the moderating role of social support and neighborhood collective efficacy. J Affect Disord. 2012;138(1):63-70.

37. De Maio FG, Kemp E. The deterioration of health status among immigrants to Canada. Glob Public Health. 2010;5(5):462-78.

38. Llacer A, Zunzunequi MV, Del Amo J, Mazarrasa L, Bolůmar F. The contribution of a gender perspective to the understanding of migrants' health. J Epidemiol Community Health. 2007;61(Suppl 2):ii4-ii10.

39. Thapa SB, Hauff E. Gender differences in factors associated with psychological distress among immigrants from low-and middle-income countries. Soc Psychiatry Psychiatr Epidemiol. 2005;40(1):78-84.

40. Aldén L, Hammarstedt M. Integration of immigrants on the Swedish labour market: recent trends and explanations: Linnaeus University Centre for Labour Market and Discrimination Studies at Linnaeus University; 2014.

41. Sweden PHAo. Hälsa på lika villkor [health on equal terms] technical report for survey 2011. 2011.

42. Sweden PHAo. Hälsa på lika villkor [health on equal terms] technical report for survey 2015. 2015.

43. Gotsens M, Malmusi D, Villarroel N, Vives-Cases C, Garcia-Subirats I, Hernando C, et al. Health inequality between immigrants and natives in Spain: the loss of the healthy immigrant effect in times of economic crisis. Eur J Pub Health. 2015;25(6):923-9.

44. Lundin A, Hallgren M, Theobald H, Hellgren C, Torgén M. Validity of the 12item version of the general health questionnaire in detecting depression in the general population. Public Health. 2016;136:66-74.

45. Statistics Sweden. Socio-economic classification [Socioekonomisk indelning (SEl)]: SCB; 1984. Avalible at: https:/www.scb.se/contentassets/ 22544e89c6f34ce7ac2e6fefbda407ef/english_ov9999_1982a01_br_x11op8204-3. pdf. Accessed 16 Mar 2019

46. Yun M-S. Decomposing differences in the first moment. Econ Lett. 2004; 82(2):275-80.

47. Fairlie RW. An extension of the blinder-Oaxaca decomposition technique to logit and probit models. J Econ Soc Meas. 2005;30(4): $305-16$.

48. San Sebastian M, Hammarstrom A, Gustafsson PE. Socioeconomic inequalities in functional somatic symptoms by social and material conditions at four life course periods in Sweden: a decomposition analysis. BMJ Open. 2015;5(8):e006581.

49. Hosseinpoor AR, Stewart Williams J, Amin A, Araujo de Carvalho I, Beard J, Boerma T, et al. Social determinants of self-reported health in women and men: understanding the role of gender in population health. PLoS One. 2012;7(4):e34799.

50. Oaxaca R. Male-female wage differentials in urban labor markets. Int Econ Rev. 1973;14(3):693-709.

51. Yun M-S. Hypothesis tests when decomposing differences in the first moment. J Econ Soc Meas. 2005;30(4):295-304.

52. Stewart Williams JA. Using non-linear decomposition to explain the discriminatory effects of male-female differentials in access to care: a cardiac rehabilitation case study. Soc Sci Med. 2009;69(7):1072-9.

53. Kosidou K, Hellner-Gumpert C, Fredlund P, Dalman C, Hallqvist J, Isacsson G, et al. Immigration, transition into adult life and social adversity in relation to psychological distress and suicide attempts among young adults. PLoS One. 2012;7(10):e46284

54. Sweden S. De första 15 åren - flyktingars försörjning i Sverige [Refugees' income sources during their first 15 years in Sweden]; 2018

55. Vogel J, Hjerm M, Johansson S-E. Integration till svensk välfärd. Om invandrares välfärd på; 2002.

56. Boulanger Martel SP, Pelling L, Wadensjö E. Economic resources, financial aid and remittances. IZA discussion papers; 2018.

57. OECD. Divided We Stand: Why Inequality Keeps Rising. SWEDEN: COUNTRY NOTE; 2011.

58. Glazier RH, Creatore Ml, Cortinois AA, Agha MM, Moineddin R. Neighbourhood recent immigration and hospitalization in Toronto, Canada. Can J Public Health. 2004;95(3):130.

59. Noh S, Kaspar V, Wickrama K. Overt and subtle racial discrimination and mental health: preliminary findings for Korean immigrants. Am J Public Health. 2007:97(7):1269-74

60. Patel K, Kouvonen A, Close C, Väänänen A, O'Reilly D, Donnelly M. What do register-based studies tell us about migrant mental health? A scoping review. Syst Rev. 2017;6(1):78. 
61. Careja R, Bevelander P. Using population registers for migration and integration research: examples from Denmark and Sweden. Comp Migr Stud. 2018;6(1):19.

62. Saraiva Leão T, Sundquist J, Johansson LM, Johansson S-E, Sundquist K. Incidence of mental disorders in second-generation immigrants in Sweden: a four-year cohort study. Ethn Health. 2005;10(3):243-56.

Ready to submit your research? Choose BMC and benefit from:

- fast, convenient online submission

- thorough peer review by experienced researchers in your field

- rapid publication on acceptance

- support for research data, including large and complex data types

- gold Open Access which fosters wider collaboration and increased citations

- maximum visibility for your research: over $100 \mathrm{M}$ website views per year

At $\mathrm{BMC}$, research is always in progress.

Learn more biomedcentral.com/submissions 